\title{
A case of rhabdomyolysis related to sorafenib treatment for advanced hepatocellular carcinoma
}

\author{
Kunihiro Tsuji $\cdot$ Kenichi Takemura $\cdot$ Keisuke Minami $\cdot$ \\ Ryota Teramoto - Keisuke Nakashima - Shinya Yamada • \\ Hisashi Doyama $\cdot$ Hisanori Oiwake $\cdot$ Kenkou Hasatani
}

Received: 28 January 2013/Accepted: 29 April 2013/Published online: 17 May 2013

(C) The Author(s) 2013. This article is published with open access at Springerlink.com

\begin{abstract}
We report on a case of rhabdomyolysis related to sorafenib treatment for advanced hepatocellular carcinoma. A 70-year-old man was admitted to our hospital with fatigue, myalgia and an elevated creatine phosphokinase level. He was diagnosed as rhabdomyolysis related to sorafenib treatment for advanced hepatocellular carcinoma. After discontinuation of sorafenib, his fatigue and myalgia resolved and his creatine phosphokinase level returned to normal. Rhabdomyolysis related to sorafenib treatment is rare adverse effect. This is the first detailed case report of rhabdomyolysis related to sorafenib treatment.
\end{abstract}

Keywords Rhabdomyolysis · Sorafenib · Adverse effect

\section{Introduction}

Sorafenib is a small molecule that inhibits multiple kinases involved in angiogenesis and tumor growth $[1,2]$. The efficacy of sorafenib for the treatment of advanced hepatocellular carcinoma (HCC) has been demonstrated in phase III randomized trials [3, 4], and sorafenib is now standard treatment for advanced HCC. The major adverse effects of sorafenib include skin rash, hand-foot skin reactions, diarrhea and hypertension.

K. Tsuji $(\bowtie) \cdot$ K. Takemura $\cdot$ S. Yamada $\cdot$ H. Doyama Department of Gastroenterology, Ishikawa Prefectural Central Hospital, 2-1 Kuratsuki-higashi, Kanazawa, Ishikawa 920-8530, Japan

e-mail: kt98052@yahoo.co.jp

K. Tsuji - K. Minami - R. Teramoto - K. Nakashima •

H. Oiwake $\cdot$ K. Hasatani

Department of General Medicine, Suzu General Hospital,

Suzu, Japan
Rhabdomyolysis related to sorafenib treatment has been identified during post-approval use of sorafenib. It is rare adverse effect. To our knowledge, there are no detailed case reports regarding rhabdomyolysis related to sorafenib treatment. Rhabdomyolysis is characterized by leakage of myoglobin and other intracellular proteins and electrolytes into the circulation, and may be associated with various diseases, injuries, medications and toxins [5]. Early recognition of drug-induced rhabdomyolysis is important for successful management [6]. Here, we report a case of rhabdomyolysis in a patient with advanced HCC who was taking sorafenib.

\section{Case report}

A 70-year-old male was admitted to our hospital in August 2012. He had a 10-year history of hepatitis $\mathrm{C}$ virus infection, and had not received interferon therapy. In August 2011, computed tomography (CT) detected a small mass (about $1.8 \times 1.6 \mathrm{~cm})$ in the right lobe of the liver, which was diagnosed as HCC. In October 2011, he underwent partial resection of the liver for HCC. About three months later, CT revealed multiple masses in the liver, which were diagnosed as recurrent HCCs. In January and March 2012, he underwent transcatheter chemoembolization of the hepatic lesions. The drugs used for one of the cycles were epirubicin $(20 \mathrm{mg})$ and lipiodol $(3 \mathrm{~mL})$. In June and July 2012, he received two cycles of intra-arterial infusion chemotherapy with cisplatin powder (IA-call) into the hepatic artery at a dose of $65 \mathrm{mg} / \mathrm{m}^{2}$. Follow-up CT showed new metastatic lesions in the liver. He had Eastern Cooperative Oncology Group performance status 0 and Child-Pugh liver function class A (Table 1). Twelve days before admission he had started sorafenib therapy (400 mg twice a day); at this 
moment, 37 days had passed since the last intra-arterial infusion chemotherapy with IA-call. He was not taking any other new medications. No major adverse effects were observed during the first week of treatment. Although the skin rash and diarrhea did not appear, fatigue and myalgia appeared at 10 days after the onset of sorafenib treatment, and his symptoms gradually worsened.

Table 1 Laboratory findings

\begin{tabular}{lll}
\hline & At the start of treatment & On admission \\
\hline WBC (per $\mu \mathrm{L})$ & 2830 & 5600 \\
Hemoglobin $(\mathrm{g} / \mathrm{dL})$ & 11.5 & 11.6 \\
Platelets $($ per $\mu \mathrm{L})$ & $11.4 \times 10^{4}$ & $3.5 \times 10^{4}$ \\
Prothrombin time $(\%)$ & 102 & 95.3 \\
Fibrinogen $(\mathrm{mg} / \mathrm{dL})$ & - & 140 \\
FDP $(\mu \mathrm{g} / \mathrm{mL})$ & - & 147.7 \\
Albumin $(\mathrm{g} / \mathrm{dL})$ & 3.0 & 2.8 \\
Total bilirubin $(\mathrm{mg} / \mathrm{dL})$ & 0.73 & 1.88 \\
AST $(\mathrm{U} / \mathrm{L})$ & 76 & 318 \\
ALT $(\mathrm{U} / \mathrm{L})$ & 46 & 101 \\
LDH $(\mathrm{U} / \mathrm{L})$ & 185 & 921 \\
CK $(\mathrm{U} / \mathrm{L})$ & 32 & 10911 \\
BUN $(\mathrm{mg} / \mathrm{dL})$ & 15.1 & 35 \\
Creatinine $(\mathrm{mg} / \mathrm{dL})$ & 0.84 & 1.17 \\
Serum myoglobin $(\mathrm{ng} / \mathrm{mL})$ & - & 3490 \\
Urine myoglobin $(\mathrm{ng} / \mathrm{mL})$ & - & 25800 \\
$\alpha-F P(\mathrm{ng} / \mathrm{mL})$ & - & 41068 \\
PIVKA-II $(\mathrm{mAU} / \mathrm{ml})$ & - & 55200 \\
\hline WBC white blood & &
\end{tabular}

$\overline{W B C}$ white blood cells, FDP fibrinogen degradation products, $A S T$ aspartate aminotransferase, $A L T$ alanine aminotransferase, $L D H$ lactate dehydrogenase, $C K$ creatine phosphokinase, $B U N$ blood urea nitrogen, $\alpha-F P$ alfa-fetoprotein, PIVKA-II protein induced by vitamin $\mathrm{K}$ absence or antagonists-II
The patient's family history was unremarkable. He had no personal history of smoking or alcohol abuse. In addition to sorafenib ( $800 \mathrm{mg} /$ day) for the past 12 days, he was taking magnesium oxide, bifidobacterium, sulpiride, ursodeoxycholic acid and alprazolam. For several years there had been no change to his drugs except for sorafenib.

Physical examination revealed blood pressure $116 / 70 \mathrm{mmHg}$, heart rate 70 beats/min and body temperature $36.4{ }^{\circ} \mathrm{C}$. He had proximal muscle weakness, but no other abnormality was observed. Laboratory testing showed increased serum creatine phosphokinase, myoglobin, aspartate aminotransferase and alanine aminotransferase levels, decreased platelet count, and increased urine myoglobin level (Table 1). Drug-induced rhabdomyolysis was suspected, and sorafenib was discontinued because the rhabdomyolysis had occurred within 2 weeks after the initiation of sorafenib treatment. The patient received infusion therapy (not including potassium) followed by a massive extracellular fluid infusion of $>3 \mathrm{~L}$ per day for 2 days. After discontinuation of sorafenib and administration of intravenous fluids, his myalgia and fatigue resolved. Once his condition improved, the infusion volume was gradually reduced. Serum creatinine remained within normal limits throughout hospitalization, and renal failure was avoided. Creatinine phosphokinase levels returned to normal within one week (Fig. 1), i.e., compared to his laboratory test results upon admission which were similar to those seen in disseminated intravascular coagulation and severe liver damage. His condition improved rapidly with discontinuation of the sorafenib and administration of intravenous fluids only. There was no recurrence of rhabdomyolysis following reintroduction of other drugs except for sorafenib. He was discharged 20 days after hospitalization, with ongoing best supportive care for his HCC.

Fig. 1 Course of laboratory parameters. After discontinuation of sorafenib treatment and administration of intravenous fluids, serum creatine phosphokinase and alanine aminotransferase levels decreased and platelet count increased. Serum level of creatine remained within normal limit throughout hospitalization

\section{$\mathrm{Cr}(\mathrm{mg} / \mathrm{dL}) \quad \mathrm{CK}(\mathrm{U} / \mathrm{L})$}

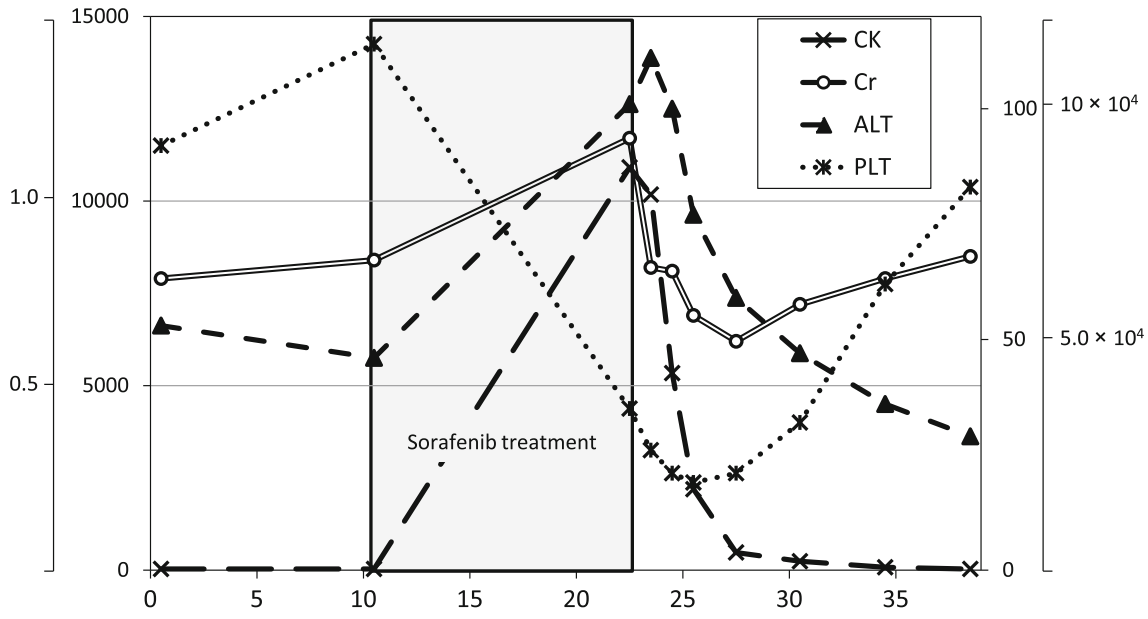




\section{Discussion}

This is the first case report of rhabdomyolysis related to sorafenib treatment. Sorafenib is an orally active multikinase inhibitor which has been approved for the treatment of advanced HCC and advanced renal cell carcinoma by the US Food and Drug Administration. Pivotal phase III randomized trials showed an overall survival benefit with sorafenib treatment, and established its efficacy and safety for the treatment of advanced HCC and advanced renal cell carcinoma [3, 4, 7, 8].

Rhabdomyolysis related to sorafenib treatment is rare. Rhabdomyolysis has been reported during post-approval use of sorafenib. Although there are no detailed reports regarding rhabdomyolysis related to sorafenib treatment for advanced HCC, nine cases have been reported to the enterprise up to March 2013 in Japan [9]. As rhabdomyolysis was reported voluntarily from a population of uncertain size, the frequency of this adverse effect remains unclear.

The mechanism of rhabdomyolysis related to sorafenib treatment is not clear. Antoun et al. [10] reported statistically significant weight loss in patients taking sorafenib, which was associated with a significant reduction in skeletal muscle mass. Although the mechanism of this muscle loss is unclear, they suggested that kinases might play an important role in the regulation of muscle protein synthesis [10].

Rhabdomyolysis has been described in patients treated with the tyrosine kinase inhibitors imatinib and sunitinib $[11,12]$. Two patients who developed severe rhabdomyolysis related to sunitinib treatment had a $>50 \%$ reduction in left ventricular ejection fraction [12]. However, our patient had a normal ejection fraction. Sorafenib rarely causes a decrease in left ventricular ejection fraction [13], whereas sunitinib is known to cause decreased left ventricular ejection fraction. The inhibition of tyrosine kinase activity by sunitinib may accompany cardiac toxicity, but it is possible that this effect does not occur with sorafenib. Recurrence of rhabdomyolysis following reintroduction of sorafenib treatment has been reported in only one case up to March 2013; however, another case reported no recurrence of sorafenib-induced rhabdomyolysis after reintroduction of sorafenib treatment [9]. Reintroduction of sorafenib treatment after drug-induced rhabdomyolysis may be dangerous, but there is currently no conclusive evidence for this.

We report a case of rhabdomyolysis related to sorafenib treatment. The therapeutic strategy for advanced HCC has not been definitively established; sorafenib treatment for advanced HCC improves survival, but median survival in Asian patients is less than that seen in Westerners [3, 4]. Intrahepatic arterial chemotherapy is often performed for intrahepatic advanced HCC in Japan. It has not yet been established whether sorafenib or chemotherapy treatment is superior for intrahepatic advanced HCC, and the results of an ongoing clinical trial are highly anticipated. In addition, since the survival benefit of intrahepatic arterial chemotherapy has not been demonstrated in randomized controlled studies, sorafenib treatment for advanced HCC seems appropriate at this time. It is important to note that rhabdomyolysis related to sorafenib treatment is a potentially life-threatening condition, and physicians need to consider the potential adverse effects of rhabdomyolysis in patients administered sorafenib.

Conflict of interest The authors declare that they have no conflict of interest.

Open Access This article is distributed under the terms of the Creative Commons Attribution License which permits any use, distribution, and reproduction in any medium, provided the original author(s) and the source are credited.

\section{References}

1. Wilhelm SM, Carter C, Tang L, et al. BAY 43-9006 exhibits broad spectrum oral antitumor activity and targets the RAF/MEK/ ERK pathway and receptor tyrosine kinases involved in tumor progression and angiogenesis. Cancer Res. 2004;64:7099-109.

2. Chang YS, Adnane J, Trail PA, et al. Sorafenib (BAY 43-9006) inhibits tumor growth and vascularization and induces tumor apoptosis and hypoxia in RCC xenograft models. Cancer Chemother Pharmacol. 2007;59:561-74.

3. Cheng AL, Kang YK, Chen Z, et al. Efficacy and safety of sorafenib in patients in the Asia-Pacific region with advanced hepatocellular carcinoma: a phase III randomized, double blind, placebo controlled trial. Lancet Oncol. 2009;10:25-34.

4. Llovet J, Ricci S, Mazzaferro V, SHARP Investigators Study Group, et al. Sorafenib in advanced hepatocellular carcinoma. N Engl J Med. 2008;359:378-90.

5. Khan FY. Rhabdomyolysis: a review of the literature. Neth $\mathbf{J}$ Med. 2009;67:272-83.

6. Prendergast BD, George CF. Drug-induced rhabdomyolysismechanisms and management. Postgrad Med J. 1993;69:333-6.

7. Escudier B, Eisen T, Stadler WM, TARGET Study Group, et al. Sorafenib in advanced clear-cell renal-cell carcinoma. N Engl J Med. 2007;356:125-34.

8. Escudier B, Eisen T, Stadier WM, et al. Sorafenib for treatment of renal cell carcinoma: final efficacy and safety results of the phase III treatment approaches in renal cancer global evaluation trial. J Clin Oncol. 2009;27:3312-8.

9. Welcome to Nexavar JP [Homepage on the Internet. Available from http://www.nexavar.jp/index.html] (in Japanese)

10. Antoun S, Birdsell L, Sawyer MB, Venner P, Escudier B, Baracos VE. Association of skeletal muscle wasting with treatment with sorafenib in patients with advanced renal cell carcinoma: results from a placebo-controlled study. J Clin Oncol. 2010;28:1054-60.

11. Penel N, Blay JY, Adenis A. Imatinib as a possible cause of severe rhabdomyolysis. N Engl J Med. 2008;358:2746-7.

12. Ruggeri EM, Cecere FL, Moscetti L, Doni L, Padalino D, Di Costanzo F. Severe rhabdomyolysis during sunitinib treatment of metastatic renal cell carcinoma. A report of two cases. Ann Oncol. 2010;21:1926-7.

13. Orphanos GS, Ioannidis GN, Ardavanis AG. Cardiotoxicity induced by tyrosine kinase inhibitors. Acta Oncol. 2009;48:964-70. 